\title{
Effect of Levothyroxine Treatment on Incident Dementia in Adults with Atrial Fibrillation and Hypothyroidism
}

\author{
Per Wändell $^{1}$ (D) . Axel C. Carlsson ${ }^{1} \cdot$ Jan Sundquist ${ }^{2,3,4,5} \cdot$ Kristina Sundquist $^{2,3,4,5}$
}

Published online: 14 December 2018

(c) The Author(s) 2018

\begin{abstract}
Background and Objective The possible adverse or positive effects of levothyroxine treatment among patients with atrial fibrillation have been debated. Atrial fibrillation, levothyroxine treatment, and dementia are common among older adults, yet little is known about the effects of levothyroxine on the development of dementia.

Methods The study population included all adults $(n=12,057)$ aged $\geq 45$ years with a diagnosis of atrial fibrillation at 75 primary care centers in Sweden during 2001-2007 without an earlier recorded dementia diagnosis. Patients with a diagnosis of hypothyroidism and levothyroxine prescription $(n=756 ; 180$ men and 576 women), or with a prescription without this diagnosis ( $n=415,100$ men and 315 women), were compared to patients without a diagnosis and prescription $(n=10,886)$. Cox regression was performed, with hazard ratios and $95 \%$ confidence intervals, with outcome defined as dementia of all causes until 31 December, 2010.

Results During a mean 5.7 years (standard deviation 2.4 years) of follow-up, a total of 749 patients with atrial fibrillation (6.2\%) were diagnosed with dementia. Women with hypothyroidism and a levothyroxine prescription showed lower hazard ratios $(0.61 ; 0.41-0.90)$ in adjusted Cox regression models (age, socioeconomic factors, co-morbidity, and warfarin treatment). Levothyroxine prescription without hypothyroidism was non-significant.

Conclusions We found that women with atrial fibrillation with levothyroxine treatment and hypothyroidism have a lower risk of incident dementia than women with atrial fibrillation without levothyroxine treatment and no hypothyroidism. The results should be confirmed in larger studies.
\end{abstract}

Electronic supplementary material The online version of this article (https://doi.org/10.1007/s40261-018-0740-3) contains supplementary material, which is available to authorized users.

Per Wändell

per.wandell@ki.se

1 Division of Family Medicine and Primary Care, Department of Neurobiology, Care Sciences and Society, Karolinska Institute, Alfred Nobels Allé 23, 14183 Huddinge, Sweden

2 Center for Primary Health Care Research, Lund University, Malmö, Sweden

3 Department of Family Medicine and Community Health, Icahn School of Medicine at Mount Sinai, New York, NY, USA

4 Department of Population Health Science and Policy, Icahn School of Medicine at Mount Sinai, New York, NY, USA

5 Center for Community-based Healthcare Research and Education (CoHRE), Department of Functional Pathology, School of Medicine, Shimane University, Matsue, Shimane, Japan

\section{Key Points}

Women with atrial fibrillation with levothyroxine treatment and hypothyroidism showed a lower risk of incident dementia than those without this treatment and diagnosis.

The effect in women with levothyroxine treatment and hypothyroidism was further exaggerated when removing the youngest and oldest women from the analyses.

Levothyroxine without a diagnosis of hypothyroidism showed no effect on incident dementia. 


\section{Introduction}

Earlier research regarding thyroid function and dementia has shown conflicting results. In a review from The Swedish Council on Health Technology Assessment in Health Care, the conclusion was that there is lack of evidence of the association between the cognitive impairment due to disturbed thyroid function and the development of dementia [1]. As dementia is not a single diagnosis but rather a cluster of different diagnoses with somewhat different risk factor patterns, a clear summary of the research field is rather difficult, with some contradictory findings. However, risk factor patterns are similar between different types of dementia [2]. One older study found hypothyroidism to be more common in patients with Alzheimer's dementia (AD) compared with those without this diagnosis [3], while another found subclinical hyperthyroidism but not subclinical hypothyroidism to be associated with an increased risk of dementia [4, 5]. A recent study found hypothyroidism to be associated with cerebrovascular diseases but not with AD pathology [6]. Higher levels of free thyroxin have repeatedly been shown to be associated with incident dementia [7, 8]. Animal models have shown hypothyroidism to induce the amyloidogenic pathway of amyloid precursor protein processing in the hippocampus [9].

Atrial fibrillation (AF) is increasingly common with age and also associated with an increased risk of dementia [10-12]. The most important factor behind the increased risk of dementia is the increased risk of cardio-embolic stroke [12], with anticoagulant treatment being the most evidence-based treatment to prevent dementia in patients with AF $[13,14]$. In an AD animal model of mice, thyroid hormones have been shown to prevent cognitive deficit [15], and in a similar way in an AD model of rats to improve histological changes and memory [16]. The dementia risk in relation to the age of onset of AF has shown conflicting results in studies of patients with AF [12]. One study found an association between AF and dementia for elderly individuals only [17], whereas another large study found the highest association in subjects younger than 70 years of age [18]. Another study analyzing the onset of $\mathrm{AD}$ in relation to age, found the most important factors for early onset of AD to be APOE haplotypes, marital status, and history of depression, whereas dementia risk in later life seemed to be influenced by prevalent cerebrovascular risk factors [19].

The relationship between hypothyroidism, levothyroxine, and survival has been elucidated in earlier research, where hypothyroidism and levothyroxine treatment was associated with a lower cardiovascular risk and mortality [20], even if the potential mechanism explaining the association between levothyroxine treatment and mortality is unknown. Women have a higher prevalence of hypothyroidism and are more commonly treated with levothyroxine [21]. Women with AF also exert a higher relative risk of stroke than men with AF [22]. Hence, we believe that men and women should be analyzed separately. The primary aim was to study the association between levothyroxine treatment and dementia among patients with $\mathrm{AF}$ and hypothyroidism in Swedish primary care.

\section{Methods}

\subsection{Study Design}

The study was based on individual-level patient data from 75 primary healthcare centers (PHCCs), 48 of which were located in Stockholm County. Individuals attending any of the participating PHCCs between 2001 and 2008 were included in the study. We used Extractor software to extract electronic patient records (EPRs) [23]. National identification numbers were replaced with new unique serial numbers to ensure anonymity. The files were linked to a database constructed using the Swedish Total Population Register, the Hospital Discharge Register, and the Swedish Cause-of-Death Register, which contains individual-level data on age, sex, education, hospital admissions, mortality, and cause of death for all residents registered in Sweden. Thus, a new research database containing clinical data and information on socioeconomic status (SES) on the individuals $(n=1,098,420)$ registered at the 75 PHCCs was created [24]. Ethical approvals were obtained from regional boards at Karolinska Institute and the University of Lund.

\subsection{Study Population}

The study included all patients with diagnosed AF, identified by the presence of the World Health Organization's International Classification of Diseases, 10th Revision for AF (I48) in EPRs in primary healthcare, and who visited any of the 75 participating PHCCs from 1 January, 2001, until 31 December, 2007. We excluded patients with an earlier diagnosis of dementia $(n=187)$, and also patients with a diagnosis of hypothyroidism without a prescription of levothyroxine $(n=39)$. Patients without data on neighborhood SES were also excluded [Table 1 of the Electronic Supplementary Material (ESM)]. In total, 12,057 individuals (6580 men and 5516 women) aged $\geq 45$ years at the time of AF diagnosis were included. Prescription of levothyroxine (H03AA01) in the EPR in at least one occasion was recorded. 


\subsection{Outcomes and Confounders}

A diagnosis of dementia of any type according to the International Classification of Diseases, 10th Revision classification in EPRs from hospitals, or from the death register, was used as the primary outcome (F00 Alzheimer's dementia, F01 Vascular dementia, F02 Dementia in other diseases classified elsewhere, F03 Unspecified dementia, F10.7A Alcohol dementia, F10.97Alcohol use, unspecified with alcoholinduced persisting dementia, or G30 Alzheimer's disease). For the primary outcome, time to diagnosis of dementia after first AF diagnosis was registered (until 31 December, 2010). Individuals were divided into the following pre-specified age groups $45-54,55-64,65-74,75-84$, and $\geq 85$ years.

Educational level was categorized according to prespecification as $\leq 9$ years (partial or complete compulsory schooling), 10-12 years (partial or complete secondary schooling), and $>12$ years (college and/or university studies). Marital status was classified as married, unmarried, divorced, or widowed. The neighborhood SES areas were categorized into three groups according the neighborhood index: > one standard deviation (SD) below the mean (high SES or low deprivation level), $>$ one SD above the mean (low SES or high deprivation level), and within one SD of the mean (middle SES or deprivation level).

The following related disorders were used as covariates (International Classification of Diseases, 10th Revision codes in the ESM): hypertension, coronary heart disease, cerebrovascular diseases, congestive heart failure (CHF), obesity, diabetes mellitus, chronic obstructive pulmonary disease (COPD), depression, or anxiety disorders (see the ESM). Patients with a prescription of levothyroxine without a registered diagnosis of hypothyroidism $(n=415)$ were identified and analyzed separately. Furthermore, $\mathrm{CHA}_{2} \mathrm{DS}_{2}-\mathrm{VASc}$ was used, i.e., an instrument for predicting ischemic stroke in patients with $\mathrm{AF}$, including congestive heart failure, hypertension, age between 65 and 74 years yields one point, and 75 years and above two points, diabetes mellitus, a history of stroke or previous transient ischemic attacks and thromboembolism two points, and the presence of any cardiovascular disease is credited with one point (recorded as myocardial infarction, peripheral artery disease, or plaque in the aorta) [25].

\subsection{Statistics}

Descriptive data were shown as mean with SD for age, otherwise by numbers and percentages. Logistic regression with odds ratios and $95 \%$ confidence intervals was performed, comparing patients with hypothyroidism and levothyroxine prescription, or patients with levothyroxine prescription without a registered diagnosis of hypothyroidism, to patients with neither a hypothyroidism diagnosis nor a levothyroxine prescription.
Cox regression with hazard ratios and $95 \%$ confidence intervals, using time to dementia as the outcome, was used in follow-up analyses for patients with hypothyroidism and levothyroxine treatment, or patients with levothyroxine prescription without a registered diagnosis of hypothyroidism, compared to patients without both a hypothyroidism diagnosis and a levothyroxine prescription. We used regression models with full adjustment, i.e., for age (and sex, when applicable), socioeconomic factors (educational level, marital status, neighborhood SES, and change of SES neighborhood), co-morbidity (hypertension, coronary heart disease, CHF, cerebrovascular diseases, obesity, diabetes, COPD, depression, and anxiety), and warfarin treatment (B01AA03). Furthermore, as risk factors for dementia differ over age, we also analyzed patients with the lowest and highest quartile of age at first recorded diagnosis of AF excluded, thus including patients aged $77-85$ years (25th-75th percentile). As a supplementary analysis, we also studied incident dementia in relation to $\mathrm{CHA}_{2} \mathrm{DS}_{2}$-VASc scores. A two-sided $p$ value of $<0.05$ was considered statistically significant for variables in the regression analyses. All analyses were performed in STATA 15.2 (StataCorp, 4905 Lakeway Drive, College Station, Texas 77845 USA).

\section{Results}

Characteristics of the study population $(n=12,057$ individuals) are shown separately for men $(n=6580)$ and women $(n=5516)$ and also divided into individuals with a diagnosis of hypothyroidism and levothyroxine treatment, patients with levothyroxine prescription without a registered diagnosis of hypothyroidism, and those without a diagnosis of hypothyroidism and no levothyroxine treatment (Table 1). Median age for dementia was 79 years among men and 81 years among women. The mean follow-up time was 5.7 years (SD 2.4), and hazard ratios were calculated based on 68,977 person-years at risk $(38,141$ person-years among men and 30,836 person-years among women). The incidence rate of all types of dementia per 100 patient-years was 0.84 (95\% confidence interval 0.76-0.94) in men, and 1.38 (95\% confidence interval 1.26-1.52) in women.

Multivariate logistic regression models for subjects with levothyroxine prescription with a diagnosis of hypothyroidism, or patients with levothyroxine prescription without a registered diagnosis of hypothyroidism, vs. subjects without hypothyroidism or levothyroxine treatment are shown in Table 2. Hypothyroidism among women was more associated with obesity and depression, and less associated with cerebrovascular diseases and new dementia. Levothyroxine treatment without a registered diagnosis of hypothyroidism among women was associated with a higher frequency of CHF, diabetes, and COPD, and associated with a lower 
Table 1 Characteristics for patients aged $\geq 45$ years with diagnoses of atrial fibrillation, categorized into patients with neither a diagnosis of hypothyroidism nor a prescription of levothyroxine, patients with a diagnosis of hypothyroidism and a prescription of levothyroxine, or patients with a prescription of levothyroxine but without a registered diagnosis of hypothyroidism $(n=12,057)$, in primary care attending 75 primary healthcare centers between 1 January, 2001 and 31 December, 2007

\begin{tabular}{|c|c|c|c|c|c|c|c|}
\hline \multirow[t]{2}{*}{ Characteristic } & \multirow[t]{2}{*}{ All } & \multicolumn{3}{|l|}{ Men with } & \multicolumn{3}{|l|}{ Women with } \\
\hline & & No hypothyroidism & Hypothyroidism & Levothyroxine only & No hypothyroidism & Hypothyroidism & $\begin{array}{l}\text { Levothyroxine } \\
\text { only }\end{array}$ \\
\hline No. of patients & 12,057 & $6293(95.7)$ & $180(2.7)$ & $100(1.5)$ & $4593(83.8)$ & $576(10.5)$ & $315(5.7)$ \\
\hline Incident dementia & $749(6.2)$ & $304(4.8)$ & $15(8.3)$ & $3(3.0)$ & $367(8.0)$ & $33(5.7)$ & $27(8.6)$ \\
\hline Deaths & 3799 (31.5) & $1842(29.3)$ & $46(25.6)$ & $44(44.0)$ & $1610(35.1)$ & $147(25.5)$ & 109 (34.6) \\
\hline $\begin{array}{l}\text { Age (years), mean } \\
\text { (SD) }\end{array}$ & $74.3(10.1)$ & $72.0(10.1)$ & $73.9(10.1)$ & $73.1(10.4)$ & $76.9(9.4)$ & $76.8(8.8)$ & $77.3(8.5)$ \\
\hline \multicolumn{8}{|l|}{ Age groups (years) } \\
\hline $45-54$ & $474(3.9)$ & $352(5.6)$ & $11(6.1)$ & $6(6.0)$ & $94(2.1)$ & $9(1.6)$ & $2(0.6)$ \\
\hline $55-64$ & $1736(14.4)$ & $1.179(18.7)$ & $22(12.2)$ & $18(18.0)$ & $439(9.6)$ & $51(8.9)$ & 27 (8.6) \\
\hline $65-74$ & $3291(27.3)$ & $1969(31.3)$ & $45(25.0)$ & $21(21.0)$ & $1034(22.5)$ & $144(25.0)$ & $78(24.8)$ \\
\hline $75-79$ & $2382(19.8)$ & $1173(18.6)$ & $42(23.3)$ & $23(23.0)$ & $950(20.7)$ & $127(22.1)$ & $67(21.3)$ \\
\hline $80-84$ & $2387(19.8)$ & $993(15.8)$ & $40(22.2)$ & $24(24.0)$ & $1118(24.3)$ & $131(22.7)$ & $81(25.7)$ \\
\hline$\geq 85$ & $1787(14.8)$ & $627(10.0)$ & $20(11.1)$ & $8(8.0)$ & $958(20.9)$ & $114(19.8)$ & $60(19.1)$ \\
\hline \multicolumn{8}{|l|}{ Educational level } \\
\hline $\begin{array}{c}\text { Compulsory } \\
\text { schooling }\end{array}$ & $4982(45.1)$ & $2350(39.4)$ & $74(43.8)$ & $31(33.3)$ & $2127(52.7)$ & $263(50.6)$ & $137(49.1)$ \\
\hline $\begin{array}{l}\text { Secondary school- } \\
\text { ing }\end{array}$ & $3940(35.6)$ & $2253(37.8)$ & $51(30.2)$ & $41(44.1)$ & $1325(32.9)$ & $173(33.3)$ & $97(34.8)$ \\
\hline $\begin{array}{l}\text { College and/ } \\
\text { or university } \\
\text { studies }\end{array}$ & $2136(19.3)$ & $1360(22.8)$ & $44(26.0)$ & $21(22.6)$ & $582(14.4)$ & $84(16.2)$ & $45(16.1)$ \\
\hline \multicolumn{8}{|l|}{ Marital status } \\
\hline Married & $5544(46.2)$ & $3752(59.8)$ & $104(58.4)$ & $55(55.0)$ & $1370(30.0)$ & $176(30.6)$ & $87(27.7)$ \\
\hline Unmarried & $1017(8.5)$ & $599(9.6)$ & $13(7.3)$ & $13(13.0)$ & $332(7.3)$ & $41(7.1)$ & $19(6.1)$ \\
\hline Divorced & 1784 (14.9) & $965(15.4)$ & $29(16.3)$ & $18(18.0)$ & $630(13.8)$ & $92(16.0)$ & $50(15.9)$ \\
\hline Widowed & $3665(30.5)$ & $955(15.2)$ & $32(18.0)$ & $14(14.0)$ & $2240(49.0)$ & $266(46.3)$ & $158(50.3)$ \\
\hline \multicolumn{8}{|c|}{ Neighborhood socioeconomic status } \\
\hline High & $4518(37.5)$ & $2510(39.9)$ & $76(42.2)$ & $38(38.0)$ & $1557(33.9)$ & $212(36.8)$ & $125(39.7)$ \\
\hline Middle & $5697(47.3)$ & $2873(45.7)$ & $80(44.4)$ & $44(44.0)$ & $2290(49.9)$ & $263(45.7)$ & $147(46.7)$ \\
\hline Low & $1842(15.3)$ & $910(14.5)$ & $24(13.3)$ & $18(18.0)$ & $746(16.2)$ & $101(17.5)$ & $43(13.7)$ \\
\hline \multicolumn{8}{|l|}{ Diagnosis } \\
\hline Hypothyroidism & $756(6.3)$ & $0(0.0)$ & $180(100.0)$ & $0(0.0)$ & $0(0.0)$ & $576(100.0)$ & $0(0.0)$ \\
\hline Hypertension & $5375(44.6)$ & $2580(41.0)$ & $86(48.8)$ & $35(35.0)$ & $2251(49.0)$ & $296(51.4)$ & $127(40.3)$ \\
\hline $\begin{array}{l}\text { Coronary heart } \\
\text { disease }\end{array}$ & $3170(26.3)$ & $1624(25.8)$ & $47(26.1)$ & $31(31.0)$ & $1216(26.5)$ & $160(28.8)$ & $92(29.2)$ \\
\hline $\begin{array}{l}\text { Congestive heart } \\
\text { failure }\end{array}$ & $5550(46.0)$ & $2688(42.7)$ & $72(40.0)$ & $58(58.0)$ & $2265(49.3)$ & $281(48.8)$ & $186(59.1)$ \\
\hline $\begin{array}{l}\text { Cerebrovascular } \\
\text { disease }\end{array}$ & 2507 (20.8) & 1197 (19.0) & $31(17.2)$ & $20(20.0)$ & $1075(23.4)$ & 103 (17.9) & $81(25.7)$ \\
\hline Obesity & $610(5.1)$ & $338(5.4)$ & $9(5.0)$ & $3(3.0)$ & $199(4.3)$ & $42(7.3)$ & $19(6.0)$ \\
\hline Diabetes mellitus & $2327(19.3)$ & $1216(19.3)$ & $44(24.4)$ & $22(22.0)$ & $860(18.7)$ & $110(19.1)$ & $75(23.8)$ \\
\hline COPD & 1395 (11.6) & $675(10.7)$ & $16(8.9)$ & $12(12.0)$ & 5598 (12.2) & $79(13.7)$ & $54(17.1)$ \\
\hline Depression & $1011(8.4)$ & $383(6.1)$ & $16(8.9)$ & $4(4.0)$ & 489 (10.7) & $90(15.6)$ & $29(9.2)$ \\
\hline Anxiety disorders & $482(4.0)$ & $172(2.7)$ & $8(4.4)$ & $1(1.0)$ & $253(5.5)$ & $31(5.4)$ & $17(5.4)$ \\
\hline Levothyroxine & $1171(9.7)$ & $0(0.0)$ & $180(100.0)$ & $100(100.0)$ & $0(0.0)$ & $576(100.0)$ & $315(100.0)$ \\
\hline Warfarin & $6356(52.7)$ & $3542(56.3)$ & $97(53.9)$ & $58(58.0)$ & $2205(48.0)$ & $285(49.5)$ & $169(53.7)$ \\
\hline
\end{tabular}

Values are expressed as n (\%) unless specified otherwise

Patients with earlier registered dementia excluded, $n=187$, and with a registered diagnosis of hypothyroidism without a prescription of levothyroxine, $n=39$. Information on educational level $(n=999)$ and marital status $(n=47)$ is missing for some individuals

$C O P D$ chronic obstructive pulmonary disease, $S D$ standard deviation 
Table 2 Multivariate logistic regression for the association for different background factors for dementia, and also newly diagnosed dementia, in AF patients, firstly for patients with hypothyroidism with levothyroxine treatment, and secondly for patients with levothy- roxine treatment without a diagnosis of hypothyroidism, vs. patients with neither dementia diagnosis nor levothyroxine treatment, in primary care patients attending any of the 75 primary healthcare centers between 1 January, 2001 and 31 December, 2007

\begin{tabular}{|c|c|c|c|c|c|c|}
\hline \multirow[t]{4}{*}{ Characteristic } & \multicolumn{3}{|c|}{ Hypothyroidism and levothyroxine treatment } & \multicolumn{3}{|c|}{$\begin{array}{l}\text { Levothyroxine treatment without a diagnosis of hypo- } \\
\text { thyroidism }\end{array}$} \\
\hline & All & Women & Men & All & Women & Men \\
\hline & $n=10,657$ & $n=4541$ & $n=6116$ & $n=10,342$ & $n=4301$ & $n=6041$ \\
\hline & OR $(95 \% \mathrm{CI})$ & OR $(95 \% \mathrm{CI})$ & OR $(95 \% \mathrm{CI})$ & OR $(95 \% \mathrm{CI})$ & OR $(95 \% \mathrm{CI})$ & OR $(95 \% \mathrm{CI})$ \\
\hline Age (years) & $1.02(1.01-1.03)$ & $1.02(1.00-1.03)$ & $1.02(1.00-1.04)$ & $1.01(0.99-1.02)$ & $1.00(0.99-1.02)$ & $1.01(0.99-1.03)$ \\
\hline \multicolumn{7}{|l|}{ Educational level } \\
\hline Compulsory schooling & 1 (ref) & & & 1 (ref) & & \\
\hline Secondary schooling & $0.97(0.81-1.17)$ & $1.06(0.86-1.31)$ & $0.73(0.50-1.07)$ & $1.22(0.96-1.55)$ & $1.15(0.87-1.52)$ & $1.53(0.94-2.50)$ \\
\hline $\begin{array}{l}\text { College and/or university } \\
\text { studies }\end{array}$ & $1.18(0.93-1.48)$ & $1.18(0.89-1.56)$ & $1.06(0.71-1.59)$ & $1.24(0.90-1.69)$ & $1.25(0.86-1.81)$ & $1.37(0.75-2.48)$ \\
\hline \multicolumn{7}{|l|}{ Marital status } \\
\hline Married & 1 (ref) & & & 1 (ref) & & \\
\hline Unmarried & $0.94(0.69-1.30)$ & $0.96(0.65-1.41)$ & $0.94(0.52-1.72)$ & $1.18(0.78-1.77)$ & $1.00(0.58-1.70)$ & $1.61(0.84-3.07)$ \\
\hline Divorced & $1.16(0.92-1.47)$ & $1.15(0.87-1.53)$ & $1.21(0.79-1.86)$ & $1.19(0.87-1.64)$ & $1.18(0.80-1.74)$ & $1.24(0.70-2.18)$ \\
\hline Widowed & $0.91(0.74-1.11)$ & $0.90(0.72-1.14)$ & $1.07(0.68-1.67)$ & $1.12(0.86-1.47)$ & $1.18(0.86-1.61)$ & $0.76(0.38-1.53)$ \\
\hline \multicolumn{7}{|l|}{ Neighborhood SES } \\
\hline High & $1.10(0.91-1.32)$ & $1.12(0.90-1.40)$ & $1.06(0.74-1.53)$ & $1.16(0.91-1.49)$ & $1.23(0.92-1.63)$ & $1.00(0.61-1.63)$ \\
\hline Middle & 1 (ref) & & & & & \\
\hline Low & $1.17(0.91-1.51)$ & $1.27(0.95-1.70)$ & $0.87(0.50-1.53)$ & $0.92(0.64-1.31)$ & $0.81(0.53-1.25)$ & $1.26(0.65-2.43)$ \\
\hline \multicolumn{7}{|l|}{ Diagnosis } \\
\hline Hypertension & $1.06(0.91-1.25)$ & $1.01(0.83-1.22)$ & $1.25(0.91-1.71)$ & $0.73(0.59-0.91)$ & $0.69(0.54-0.89)$ & $0.86(0.56-1.33)$ \\
\hline Coronary heart disease & $1.07(0.89-1.29)$ & $1.09(0.88-1.35)$ & $1.00(0.70-1.43)$ & $1.05(0.82-1.34)$ & $1.03(0.78-1.37)$ & $1.15(0.72-1.83)$ \\
\hline Congestive heart failure & $0.90(0.76-1.06)$ & $0.95(0.78-1.16)$ & $0.77(0.55-1.07)$ & $1.48(1.18-1.86)$ & 1.39 (1.07-1.82) & $1.70(1.10-2.64)$ \\
\hline Cerebrovascular diseases & $0.74(0.60-0.91)$ & $0.72(0.57-0.92)$ & $0.76(0.50-1.15)$ & $1.10(0.85-1.41)$ & $1.15(0.87-1.53)$ & $0.95(0.55-1.62)$ \\
\hline Obesity & $1.51(1.09-2.09)$ & $1.78(1.23-2.58)$ & $0.87(0.41-1.82)$ & $1.17(0.74-1.87)$ & $1.46(0.87-2.44)$ & $0.55(0.17-1.78)$ \\
\hline Diabetes mellitus & $1.09(0.89-1.34)$ & $0.99(0.78-1.26)$ & $1.38(0.95-1.99)$ & $1.33(1.03-1.71)$ & $1.40(1.04-1.88)$ & $1.17(0.70-1.95)$ \\
\hline COPD & $0.98(0.76-1.25)$ & $1.02(0.77-1.34)$ & $0.82(0.48-1.41)$ & $1.38(1.04-1.84)$ & $1.46(1.06-2.02)$ & $1.13(0.61-2.11)$ \\
\hline Depression & $1.54(1.21-1.95)$ & $1.53(1.17-2.00)$ & $1.53(0.88-2.64)$ & $0.75(0.50-1.11)$ & $0.74(0.48-1.15)$ & $0.75(0.27-2.10)$ \\
\hline Anxiety & $1.01(0.71-1.45)$ & $0.90(0.60-1.35)$ & $1.66(0.78-3.55)$ & $0.98(0.59-1.64)$ & $1.07(0.63-1.84)$ & $0.43(0.06-3.15)$ \\
\hline New dementia & $0.86(0.62-1.20)$ & $0.67(0.44-1.00)$ & $1.72(0.98-3.01)$ & $0.82(0.53-1.26)$ & $0.91(0.57-1.43)$ & $0.41(0.10-1.70)$ \\
\hline Warfarin treatment & $1.00(0.85-1.18)$ & $1.03(0.85-1.24)$ & $0.94(0.69-1.29)$ & $1.18(0.95-1.47)$ & $1.24(0.96-1.59)$ & $1.03(0.67-1.57)$ \\
\hline
\end{tabular}

ORs and $95 \% \mathrm{CI}$, for patients aged $\geq 45$ years with diagnoses of $\mathrm{AF}$ ( $n=11,209$ patients). Information on educational level ( $n=1042)$ and marital status $(n=51)$ was missing for some individuals, giving lower numbers than in Table 1

Bold values are statistically significant

$A F$ atrial fibrillation, $C I$ confidence interval, $C O P D$ chronic obstructive pulmonary disease, $O R S$ odds ratios, ref reference, $S E S$ socioeconomic status

frequency of hypertension. In men, levothyroxine treatment without a registered diagnosis of hypothyroidism was associated with a higher frequency of CHF.

Table 3 shows Cox regression models for incident dementia for subjects with hypothyroidism and levothyroxine treatment, or levothyroxine treatment without a registered diagnosis of hypothyroidism, vs. subjects with neither diagnosis nor treatment. The hazard ratio was decreased in women, and also further decreased when excluding women in the lowest and highest quartiles of age. In women and men combined, the relative risk was also significantly lower but only when excluding the lowest and highest quartiles of age. In the group with levothyroxine without a registered diagnosis of hypothyroidism, no such effect was seen (results for men and women combined only shown).

We also analyzed incident dementia in relation to $\mathrm{CHA}_{2} \mathrm{DS}_{2}$-VASc scores (Table 1 of the ESM), with exclusion of subjects with levothyroxine treatment without a 
Table 3 Cox regression models for newly diagnosed dementia among patients with atrial fibrillation $(n=12,057)$ aged $45-104$ years with a diagnosis of hypothyroidism and prescribed levothyroxine or with prescribed levothyroxine without this diagnosis, compared with those without a diagnosis of hypothyroidism or prescribed levothyroxine only

\begin{tabular}{lcc}
\hline & All ages & Age 77-85 years \\
& HR $(95 \% \mathrm{CI})$ & HR $(95 \% \mathrm{CI})$ \\
\hline \multicolumn{2}{l}{ Hypothyroidism and prescribed levothyroxine } \\
All & $0.74(0.54-1.01)$ & $\mathbf{0 . 4 9}(\mathbf{0 . 3 1 - 0 . 7 8})$ \\
Women & $\mathbf{0 . 6 1}(\mathbf{0 . 4 1 - 0 . 9 0 )}$ & $\mathbf{0 . 4 1}(\mathbf{0 . 2 3 - 0 . 7 3})$ \\
Men & $1.11(0.66-1.89)$ & $0.76(0.35-1.66)$ \\
Levothyroxine without a registered diagnosis of hypothyroidism \\
All & $0.94(0.76-1.15)$ & $0.97(0.76-1.23)$ \\
\hline
\end{tabular}

Estimates are shown for all ages, and also stratified by omitting patients below the 25 th percentile and above the 75 th percentile

Fully adjusted estimates are shown: adjusted for age, sex, socioeconomic factors (with interaction term between age and marital status), co-morbidity (with interaction terms between age and congestive heart failure, and age and cerebrovascular disease), and warfarin treatment

HR in Cox regression models and 95\% CI are shown

Bold values are statistically significant

$C I$ confidence interval, $H R$ hazard ratio

registered diagnosis of hypothyroidism. Among men, a significant trend was found, both with regard to individuals without hypothyroidism $(p<0.001)$, and with hypothyroidism and levothyroxine treatment $(p=0.021)$, while no such association was found among women.

\section{Discussion}

\subsection{Main Findings}

The main finding of this study was that women with AF and hypothyroidism and prescribed levothyroxine treatment had a lower risk of dementia than women with $\mathrm{AF}$ without hypothyroidism and prescribed levothyroxine treatment. No effect on incident dementia in patients with prescribed levothyroxine treatment without a registered diagnosis of hypothyroidism was seen.

\subsection{Comparison with Earlier Research}

Earlier studies have shown conflicting results, with an earlier review concluding that there is no association between cognitive disturbances and dementia due to thyroid dysfunction [1]. However, in some studies, thyroid dysfunction is described as a risk factor for dementia, both with regard to hyper- and hypothyroidism, and even in subclinical disorders $[4,5]$. Furthermore, there are studies showing an increased risk of cerebrovascular diseases associated with treated hypothyroidism [3, 6], which contrasts our findings of a lower risk of dementia, and a lower association with cerebrovascular diseases, in women with AF and hypothyroidism. In an earlier study, we found cerebrovascular diseases to be associated with prevalent dementia among men in all ages and among women aged younger than 75 years, while cerebrovascular diseases were negatively associated with incident dementia among women [26].

We also chose to perform analyses with exclusion of the lowest and highest quartile of age of onset of AF, as types of dementia differ during life, with unusual diseases leading to special forms of dementia being more common among younger subjects $[27,28]$. If an effect by levothyroxine should be expected to be seen, it should most probably be in the ages between the youngest and the oldest age groups, which also was the case in the present study.

Thus, we can only conclude that there are different findings regarding the association between hypothyroidism, cerebrovascular diseases, and dementia for which we have no good explanation, and this needs to be further explored. It is possible that the role of AF is limited in the present study, and that it should be viewed as a study of high-risk patients for dementia. Thus, our results, in general, may also be valid in patients with thyroid dysfunction.

\subsection{Possible Mechanism of Levothyroxine Effect on Dementia Development}

Thyroid hormones are important in the development of the brain in early life, with otherwise deleterious effects such as in congenital hypothyroidism [29, 30]. Thyroid hormones are also positively related to memory even in euthyroid men [31]. In addition, hypothyroidism is associated with depression in a bi-directional manner [32], and depression is a risk factor in itself for dementia [33]. Furthermore, an improvement of oxidative status in women with hypothyroidism is shown [34]. Results from animal models show different possible mechanisms, e.g., improvement in hippocampus function [35], and possibly also an augmentation of cholinergic activity [36].

\subsection{Results in Patients with Levothyroxine but Without Hypothyroidism}

Around $35 \%$ of patients treated with levothyroxine were not registered with a diagnosis of hypothyroidism. This group showed a different pattern compared with patients with hypothyroidism and subsequent levothyroxine treatment. The reason for levothyroxine treatment in this group is unknown. One possibility is that the patients were not taken care of in primary care, which could be the reason why we could not confirm a diagnosis of hypothyroidism, even if 
this seems unlikely as they were prescribed levothyroxine. It is also unclear why this group was not found to exhibit a lower risk of incident dementia. CHF was more common in both men and women with levothyroxine prescription but without a diagnosis of hypothyroidism. In an earlier study, we found CHF positively associated with prevalent dementia but negatively with incident dementia [26]. Furthermore, being registered with a diagnosis of hypothyroidism has been shown to be associated with a lower mortality risk compared with only a levothyroxine prescription among both men and women with AF [20].

A major strength of this study was that we were able to link clinical data from individual EPRs to data from national demographic and socioeconomic registers with $<1 \%$ of information missing. As already mentioned, we also supplied diagnoses from primary health care EPRs with hospital diagnoses of dementia, CHF, coronary heart disease, and cardiovascular disease. Moreover, randomized controlled trials often exclude individuals with co-morbidities such as patients with AF with concomitant diabetes and CHF. In the current study, we were able to include these patients in the analyses, which means that the findings are more representative of the variety of patients encountered in clinical practice today.

\section{Conclusions and Limitations}

We found women with hypothyroidism and levothyroxine treatment to have a lower risk of dementia than women with AF without hypothyroidism and no levothyroxine treatment. Levothyroxine treatment without a registered diagnosis of hypothyroidism showed no such effect. Although the results are interesting, they have to be confirmed in larger studies.

There are several limitations of this study that must be kept in mind when interpreting the results. The number of men with AF and levothyroxine treatment was low, limiting possible conclusions in men. However, the number of female patients was considerably larger. We included patients with AF registered in primary care, and another study showed that $36 \%$ of all registered patients with AF in Stockholm County were not registered with a diagnosis in primary healthcare [37]. Clinical diagnoses were mostly taken from EPRs in primary care, however, with the addition of diagnoses from hospital for dementia, CHF, myocardial infarction, and stroke. Furthermore, we did not have access to the use of sedative, hypnotic, or anticholinergic drugs. Another limitation is the study design, i.e., an observational study. Like in every observational cohort study, there may have been residual confounding present. The findings may have been subject to survival treatment selection bias [38], meaning that those treated live longer and may thus have a higher risk of developing dementia. We have earlier found that $\mathrm{CHF}$ and cerebrovascular diseases in patients with $\mathrm{AF}$ are associated with an increased mortality [39].

As dementia is not a single diagnosis, grouping all separate diagnoses into an overall dementia diagnosis is questionable, especially as risk factors for the different dementia diagnoses differ. In the present study, we grouped all dementia diagnoses together to be able to have enough statistical power for the analyses. However, this is also performed in other studies as well $[4,8,10]$, and in the clinical situation this is more relevant for doctors as well as patients. As dementia is a cluster of disorders developing over many years, patients may die as a result of other causes before getting a dementia diagnosis, i.e., because of a competing risk, which could affect the results. We did not have access to whether levothyroxine treatment was used on a long-term basis, although in most cases treatment with levothyroxine is lifelong. Moreover, AF could not be classified as paroxysmal, persistent, or permanent and heart rhythm could not be classified as sinus rhythm or fibrillation rhythm. Additionally, we had no access to kidney function.

Author Contributions PW, ACC, JS, and KS designed the study, PW and ACC analyzed the data, and all authors participated in the interpretation of the data; PW and ACC drafted the manuscript and JS and KS revised it critically for important intellectual content.

\section{Compliance with Ethical Standards}

Funding This work was supported by ALF funding ("Avtal om Läkarutbildning och Forskning", in English "Agreement on Medical Education and Research") awarded to Jan Sundquist and Kristina Sundquist and by grants from the Swedish Research Council (awarded to Kristina Sundquist), the Swedish Council for Working Life and Social Research (awarded to Jan Sundquist), and the National Heart, Lung, and Blood Institute of the National Institutes of Health under Award Number R01HL116381 (awarded to Kristina Sundquist)

Conflict of interest Per Wändell, Axel C. Carlsson, Jan Sundquist, and Kristina Sundquist have no conflicts of interest that are directly relevant to the contents of this article.

Ethics approval All procedures in this study were in accordance with the 1964 Helsinki Declaration (and its amendments). The study was approved by the Regional Ethical Boards at Karolinska Institute (Diarie numbers $12 / 2000$ and 2002-09-19) and the University of Lund (Diarie number 409/2008, with addition 19/1 2010).

Consent to participate No written informed consent was obtained from patients, as the study used anonymous register data.

Open Access This article is distributed under the terms of the Creative Commons Attribution-NonCommercial 4.0 International License (http://creativecommons.org/licenses/by-nc/4.0/), which permits any noncommercial use, distribution, and reproduction in any medium, provided you give appropriate credit to the original author(s) and the source, provide a link to the Creative Commons license, and indicate if changes were made. 


\section{References}

1. The Swedish Council on Technology Assessment in Health Care (SBU), editor. Dementia: etiology and epidemiology. Stockholm: SBU; 2008.

2. Beydoun MA, Beydoun HA, Gamaldo AA, Teel A, Zonderman AB, Wang Y. Epidemiologic studies of modifiable factors associated with cognition and dementia: systematic review and meta-analysis. BMC Public Health. 2014;14:643. https://doi. org/10.1186/1471-2458-14-643.

3. Landin K, Blennow K, Wallin A, Gottfries CG. Low blood pressure and blood glucose levels in Alzheimer's disease: evidence for a hypometabolic disorder? J Intern Med. 1993;233(4):357-63.

4. Aubert CE, Bauer DC, da Costa BR, Feller M, Rieben C, Simonsick EM, Yaffe K, Rodondi N. The association between subclinical thyroid dysfunction and dementia: the Health, Aging and Body Composition (Health ABC) Study. Clin Endocrinol (Oxf). 2017;87(5):617-26. https://doi.org/10.1111/cen.13458.

5. Rieben C, Segna D, da Costa BR, Collet TH, Chaker L, Aubert CE, Baumgartner C, Almeida OP, Hogervorst E, Trompet S, Masaki K, Mooijaart SP, Gussekloo J, Peeters RP, Bauer DC, Aujesky D, Rodondi N. Subclinical thyroid dysfunction and the risk of cognitive decline: a meta-analysis of prospective cohort studies. J Clin Endocrinol Metab. 2016;101(12):4945-54. https ://doi.org/10.1210/jc.2016-2129.

6. Brenowitz WD, Han F, Kukull WA, Nelson PT. Treated hypothyroidism is associated with cerebrovascular disease but not Alzheimer's disease pathology in older adults. Neurobiol Aging. 2018;62:64-71. https://doi.org/10.1016/j.neurobiola ging.2017.10.004.

7. Yeap BB, Alfonso H, Chubb SA, Puri G, Hankey GJ, Flicker L, Almeida OP. Higher free thyroxine levels predict increased incidence of dementia in older men: the Health in Men Study. J Clin Endocrinol Metab. 2012;97(12):E2230-7. https://doi. org/10.1210/jc.2012-2108.

8. Wu Y, Pei Y, Wang F, Xu D, Cui W. Higher FT4 or TSH below the normal range are associated with increased risk of dementia: a meta-analysis of 11 studies. Sci Rep. 2016;6:31975. https:// doi.org/10.1038/srep31975.

9. Ghenimi N, Alfos S, Redonnet A, Higueret P, Pallet V, Enderlin V. Adult-onset hypothyroidism induces the amyloidogenic pathway of amyloid precursor protein processing in the rat hippocampus. J Neuroendocrinol. 2010;22(8):951-9. https://doi. org/10.1111/j.1365-2826.2010.02002.x

10. Aldrugh S, Sardana M, Henninger N, Saczynski JS, McManus DD. Atrial fibrillation, cognition and dementia: a review. J Cardiovasc Electrophysiol. 2017;28(8):958-65. https://doi. org/10.1111/jce.13261.

11. Jacobs V, Cutler MJ, Day JD, Bunch TJ. Atrial fibrillation and dementia. Trends Cardiovasc Med. 2015;25(1):44-51. https:// doi.org/10.1016/j.tcm.2014.09.002.

12. Shah AD, Merchant FM, Delurgio DB. Atrial fibrillation and risk of dementia/cognitive decline. J Atr Fibrillation. 2016;8(5):1353. https://doi.org/10.4022/jafib.1353.

13. Graves KG, May HT, Jacobs V, Bair TL, Stevens SM, Woller SC, Crandall BG, Cutler MJ, Day JD, Mallender C, Osborn JS, Peter Weiss J, Jared Bunch T. Atrial fibrillation incrementally increases dementia risk across all CHADS2 and CHA2DS2VASc strata in patients receiving long-term warfarin. Am Heart J. 2017;188:93-8. https://doi.org/10.1016/j. ahj.2017.02.026.

14. Viscogliosi G, Ettorre E, Chiriac IM. Dementia correlates with anticoagulation underuse in older patients with atrial fibrillation. Arch Gerontol Geriatr. 2017;72:108-12. https://doi.org/10.1016/j. archger.2017.05.014.
15. Fu AL, Zhou CY, Chen X. Thyroid hormone prevents cognitive deficit in a mouse model of Alzheimer's disease. Neuropharmacology. 2010;58(4-5):722-9. https://doi.org/10.1016/j.neuro pharm.2009.12.020.

16. Farbood Y, Shabani S, Sarkaki A, Mard SA, Ahangarpour A, Khorsandi L. Peripheral and central administration of T3 improved the histological changes, memory and the dentate gyrus electrophysiological activity in an animal model of Alzheimer's disease. Metab Brain Dis. 2017;32(3):693-701. https://doi. org/10.1007/s11011-016-9947-2.

17. Rusanen M, Kivipelto M, Levalahti E, Laatikainen T, Tuomilehto J, Soininen H, Ngandu T. Heart diseases and long-term risk of dementia and Alzheimer's disease: a population-based CAIDE study. J Alzheimers Dis. 2014;42(1):183-91. https://doi. org/10.3233/JAD-132363.

18. Bunch TJ, Weiss JP, Crandall BG, May HT, Bair TL, Osborn JS, Anderson JL, Muhlestein JB, Horne BD, Lappe DL, Day JD. Atrial fibrillation is independently associated with senile, vascular, and Alzheimer's dementia. Heart Rhythm. 2010;7(4):433-7. https://doi.org/10.1016/j.hrthm.2009.12.004.

19. de Oliveira FF, Bertolucci PH, Chen ES, Smith MC. Assessment of risk factors for earlier onset of sporadic Alzheimer's disease dementia. Neurol India. 2014;62(6):625-30. https://doi. org/10.4103/0028-3886.149384.

20. Wandell P, Carlsson AC, Holzmann MJ, Arnlov J, Sundquist J, Sundquist K. Comparison of mortality and nonfatal cardiovascular events in adults with atrial fibrillation with versus without levothyroxine treatment. Am J Cardiol. 2017;120(11):1974-9. https ://doi.org/10.1016/j.amjcard.2017.08.013.

21. Virta LJ, Eskelinen SI. Prevalence of hypothyroidism in Finland: a nationwide prescription study. Eur J Clin Pharmacol. 2011;67(1):73-7. https://doi.org/10.1007/s00228-010-0884-4.

22. Michelena HI, Powell BD, Brady PA, Friedman PA, Ezekowitz MD. Gender in atrial fibrillation: ten years later. Gend Med. 2010;7(3):206-17. https://doi.org/10.1016/j.genm.2010.06.001.

23. Stockholm County Council. Extractor. Available from: http:// www.slso.sll.se/SLPOtemplates/SLPOPage110400.aspx.ed. Accessed 8 Dec 2018.

24. Carlsson AC, Wandell P, Sundquist K, Johansson SE, Sundquist J. Differences and time trends in drug treatment of atrial fibrillation in men and women and doctors' adherence to warfarin therapy recommendations: a Swedish study of prescribed drugs in primary care in 2002 and 2007. Eur J Clin Pharmacol. 2013;69(2):245-53. https://doi.org/10.1007/s00228-012-1322-6.

25. Lip GY, Frison L, Halperin JL, Lane DA. Identifying patients at high risk for stroke despite anticoagulation: a comparison of contemporary stroke risk stratification schemes in an anticoagulated atrial fibrillation cohort. Stroke. 2010;41(12):2731-8. https://doi. org/10.1161/STROKEAHA.110.590257.

26. Wandell P, Carlsson AC, Sundquist J, Sundquist K. The association between relevant comorbidities and dementia in patients with atrial fibrillation. Geroscience. 2018;40(3):317-24. https:// doi.org/10.1007/s11357-018-0029-8.

27. Canadian Study of Health and Aging Working Group. Canadian study of health and aging: study methods and prevalence of dementia. CMAJ. 1994;150(6):899-913.

28. Harvey RJ, Skelton-Robinson M, Rossor MN. The prevalence and causes of dementia in people under the age of 65 years. J Neurol Neurosurg Psychiatry. 2003;74(9):1206-9.

29. Rovet JF. The role of thyroid hormones for brain development and cognitive function. Endocr Dev. 2014;26:26-43. https://doi. org/10.1159/000363153.

30. Kollati Y, Ambati RR, Reddy PN, Kumar NSS, Patel RK, Dirisala VR. Congenital hypothyroidism: facts, facets and therapy. Curr Pharm Des. 2017;23(16):2308-13. https://doi.org/10.2174/13816 12823666170206124255 . 
31. Prinz PN, Scanlan JM, Vitaliano PP, Moe KE, Borson S, Toivola B, Merriam GR, Larsen LH, Reed HL. Thyroid hormones: positive relationships with cognition in healthy, euthyroid older men. J Gerontol A Biol Sci Med Sci. 1999;54(3):M111-6.

32. Siegmann EM, Muller HHO, Luecke C, Philipsen A, Kornhuber J, Gromer TW. Association of depression and anxiety disorders with autoimmune thyroiditis: a systematic review and meta-analysis. JAMA Psychiatry. 2018;75(6):577-84. https://doi.org/10.1001/ jamapsychiatry.2018.0190.

33. Bennett $\mathrm{S}$, Thomas AJ. Depression and dementia: cause, consequence or coincidence? Maturitas. 2014;79(2):184-90. https://doi. org/10.1016/j.maturitas.2014.05.009.

34. Masullo LF, Magalhaes RA, Lemes RPG, de Almeida Filho TP, de Castro MF, Maia Filho PA, Cunha TOV, Quidute ARP, Fontenele EGP, Sun G, Martins MRA. Levothyroxine replacement improves oxidative status in primary hypothyroidism. Front Endocrinol (Lausanne). 2018;9:655. https://doi.org/10.3389/fendo .2018.00655.

35. Rivas M, Naranjo JR. Thyroid hormones, learning and memory. Genes Brain Behav. 2007;6(Suppl. 1):40-4. https://doi. org/10.1111/j.1601-183X.2007.00321.x.
36. Smith JW, Evans AT, Costall B, Smythe JW. Thyroid hormones, brain function and cognition: a brief review. Neurosci Biobehav Rev. 2002;26(1):45-60.

37. Forslund T, Wettermark B, Wandell P, von Euler M, Hasselstrom J, Hjemdahl P. Risk scoring and thromboprophylactic treatment of patients with atrial fibrillation with and without access to primary healthcare data: experience from the Stockholm health care system. Int J Cardiol. 2013;170(2):208-14. https://doi.org/10.1016/j. ijcard.2013.10.063.

38. Delgado-Rodriguez M, Llorca J. Bias. J Epidemiol Community Health. 2004;58(8):635-41. https://doi.org/10.1136/ jech.2003.008466.

39. Wandell P, Carlsson AC, Holzmann MJ, Arnlov J, Sundquist J, Sundquist K. Mortality in patients with atrial fibrillation and common co-morbidities: a cohort study in primary care. Ann Med. 2018;50(2):156-63. https://doi.org/10.1080/07853 890.2017.1407036. 